\title{
BMJ Open Sacrifice and solidarity: a qualitative study of family experiences of death and bereavement in critical care settings during the pandemic
}

Brittany Dennis (D) , ${ }^{1}$ Meredith Vanstone, ${ }^{2}$ Marilyn Swinton, ${ }^{3}$ Daniel Brandt Vegas, ${ }^{1}$ Joanna C Dionne (D) , ${ }^{1,4}$ Andrew Cheung, ${ }^{1}$ France J Clarke, ${ }^{4,5}$ Neala Hoad, ${ }^{5}$ Anne Boyle, ${ }^{2}$ Jessica Huynh, ${ }^{1}$ Feli Toledo, ${ }^{6}$ Mark Soth, ${ }^{1,5}$ Thanh H Neville, ${ }^{7}$ Kirsten Fiest (D) , ${ }^{8}$ Deborah J Cook ${ }^{1,4,5}$

To cite: Dennis B, Vanstone M, Swinton M, et al. Sacrifice and solidarity: a qualitative study of family experiences of death and bereavement in critical care settings during the pandemic. BMJ Open 2022;12:e058768. doi:10.1136/ bmjopen-2021-058768

- Prepublication history and additional supplemental material for this paper are available online. To view these files, please visit the journal online (http://dx.doi.org/10.1136/ bmjopen-2021-058768).

Received 01 November 2021 Accepted 05 January 2022
Check for updates

(C) Author(s) (or their employer(s)) 2022. Re-use permitted under CC BY-NC. No commercial re-use. See rights and permissions. Published by BMJ.

For numbered affiliations see end of article.

Correspondence to Professor Deborah J Cook; debcook@mcmaster.ca

\section{ABSTRACT}

Background Pandemic-related restrictions are expected to continue to shape end-of-life care and impact the experiences of dying hospitalised patients and their families.

Objective To understand families' experiences of loss and bereavement during and after the death of their loved one amidst the SARS-CoV-2 (COVID-19) pandemic.

Design Qualitative descriptive study.

Setting Three acute care units in a Canadian tertiary care hospital.

Participants Family members of 28 hospitalised patients who died from March-July 2020.

Main outcome measures Qualitative semistructured interviews conducted 6-16 months after patient death inquired about family experiences before and beyond the death of their loved one and garnered suggestions to improve end-of-life care.

Results Pandemic restrictions had consequences for families of dying hospitalised patients. Most family members described an attitude of acquiescence, some framing their experience as a sacrifice made for the public good. Families appreciated how clinicians engendered trust in the name of social solidarity while trying to mitigate the negative impact of family separation. However, fears about the patient's experience of isolation and changes to postmortem rituals also created despair and contributed to long-lasting grief. Conclusion Profound loss and enduring grief were described by family members whose final connections to their loved one were constrained by pandemic circumstances. Families observed solidarity among clinical staff and experienced a sense of unity with staff, which alleviated some distress. Their suggestions to improve end-of-life care given pandemic restrictions included frequent, flexible communication, exceptions for family presence when safe, and targeted efforts to connect patients whose isolation is intensified by functional impairment or limited technological access.

Trial registration number NCT04602520; Results.

\section{INTRODUCTION}

As mortality associated with serious SARSCoV-2 (COVID-19) infection continues, ${ }^{1-5}$ so
Strengths and limitations of this study

- Strengths of this study include a focus on family experiences of loss and bereavement both within and beyond hospital exposure.

- Results from this work garnered suggestions for improving end-of-life care during pandemic times, which included frequent, flexible and transparent communication to help alleviate distressing images of patients dying alone as well as targeted attention for patients with language barriers or physical and/ or cognitive impairments, who are especially impacted by the absence of their family.

- This study extends prior work in a larger sample of 28 families in the North American setting, with a higher participation rate and range of relationships.

- Limitations include a predominantly white, Englishspeaking sample from the first pandemic wave in the context of a publicly funded healthcare system.

- Results may differ for individuals with more videoconferencing access and ability, in communities with a different COVID-19 prevalence and vaccination penetrance and in different healthcare systems.

do public health measures that restrict family presence in hospital. ${ }^{6}$ Minimal personal contact and maximal barrier precautions profoundly affect the experiences of living, visiting and dying in hospital. ${ }^{6}$ While facilitating an intimate environment for compassionate end-of-life (EOL) care can be difficult at the best of times, the COVID-19 pandemic has made providing personalised care for dying patients and their families more challenging. $^{7-10}$

With ongoing infection rates, pandemic restrictions are expected to impact hospitalised patients, their families and healthcare providers for months to come. ${ }^{11}$ Research is beginning to emerge directly from family members on the impact of losing a loved one 
during the pandemic. ${ }^{12-17}$ In a Veterans Affairs survey, families of dying patients in acute hospital care, nursing home and hospice settings reported poor communication with the healthcare team and fear of patients dying alone as leading contributors to their experiences of distress. ${ }^{15}$ Other qualitative work investigating the experiences of grieving family members describe suffering driven by the separation from their loved ones, an inability to establish strong bonds with staff and an interruption of common death rituals. ${ }^{1216}$ The forced separation of patients from their family has also troubled clinicians worldwide. ${ }^{10}$ 18-21

Given the tension between pandemic public health mandates and the desire of many relatives to visit their hospitalised family member, the objective of this study was to understand experiences of loss and bereavement for families of dying patients during the pandemic and garner suggestions for comforting practices in this context.

\section{METHODS}

In this post-positivist qualitative descriptive study, ${ }^{22}{ }^{23}$ we contacted families of patients who died in hospital during the first wave of the COVID-19 pandemic between 16 March and 1 July 2020 in three acute care units (ICU, medical step down and COVID-19 ward) at a universityaffiliated hospital in Canada. Following a study of hospital-based clinicians to understand adaptations to EOL care during the pandemic, ${ }^{10}$ family members of those patients were invited by telephone to an interview to understand how their experience of loss and bereavement was influenced by the pandemic. We attempted to recruit one family member or friend as the designated next-of-kin for each patient based on documentation in the medical chart. Family member recruitment was delayed 6-12 months after the patient's death to honour the anticipated grieving process.

Employing qualitative description methods, ${ }^{23}$ we used a semi-structured interview guide developed and piloted with our interprofessional research team (online supplemental appendix) who have expertise in critical care medicine, nursing, and respiratory therapy, qualitative research, and spiritual care. Domains included: general experiences of loss and bereavement; influences of pandemic-related hospital policies; videoconferencing technology; and memorial rituals. Interviews were conducted by two trained female interviewers (BD and MS), one of whom is a resident physician (BD). Participants were given the choice of being interviewed by telephone or videoconferencing and of having their interview audio-recorded or having notes taken in place of recording. Verbal informed consent was recorded prior to the interview. Demographic data were captured using open-ended questions.

\section{Data analysis}

Transcripts were analysed using conventional qualitative content analysis. ${ }^{24}$ After an initial phase of open coding to condense and summarise the data, focused codes were developed through discussion with the research team. New data were compared with emerging analytic concepts for refinement using a constant comparative approach ${ }^{25}$ during serial investigator meetings. Rigour was ensured by triangulating findings between analysts and participants and through the development of memos through the data collection and analysis process to form an audit trail. ${ }^{26}{ }^{27}$ Descriptive statistics were used to quantitatively summarise family demographic data.

\section{Patient and public involvement}

Patient and public involvement were sought during the development of the original 3 Wishes Project protocol. ${ }^{10}$ The 3 Wishes Project is an EOL intervention aimed to honour dying patients and support families in grief. It has grown into a programme of research aimed at improving EOL care across critical and acute care settings. ${ }^{28-30}$ Many studies have emerged from the larger multicentre research programme, ${ }^{28-30}$ demonstrating feasibility, scalability, transferability and value. Due to expedited study processes during the COVID-19 pandemic, dying patients, their loved ones and the public were not directly involved in the design of this study.

\section{RESULTS}

\section{Participants}

Of 45 deceased patients included in the original study, ${ }^{10}$ we were unable to locate a surrogate decision maker for seven patients (eg, no family, changed addresses and no telephone). We contacted family members for 38 patients (figure 1). Of these, seven (18.4\%) declined to participate, one due to lack of interest and six explaining their difficulty coping with the death of their loved one. Of 31 family members who agreed to participate, three $(9.7 \%)$ interviews were not completed due to loss to follow-up. Of 28 family members interviewed, 2 were partners, 4 were parents, 14 were children and eight had other relationships with the deceased (table 1). Participants mean age was 55.5 years (SD 12.0); most identified as white (24, $85.7 \%$ ), with Christian religious affiliations (18, 64.3\%).

From February to July 2021, 28 interviews were conducted at a mean of 9.4 (SD 1.8) months after the patient's death. While 27 participants allowed audiorecording, one preferred written notes.

\section{Qualitative analysis}

Analysis of interview data yielded insight on the experiences of families whose loved one died in hospital, organised into four categories that emphasise the concepts of sacrifice and solidarity. Participants expressed prevailing acceptance of public health policies, some with an attitude of acquiescence to restrictions for the greater good. These policies keeping loved ones at a distance had a dual effect, both exacerbating and mitigating common EOL care challenges within and beyond the hospital. Families universally appreciated clinician efforts to maintain 


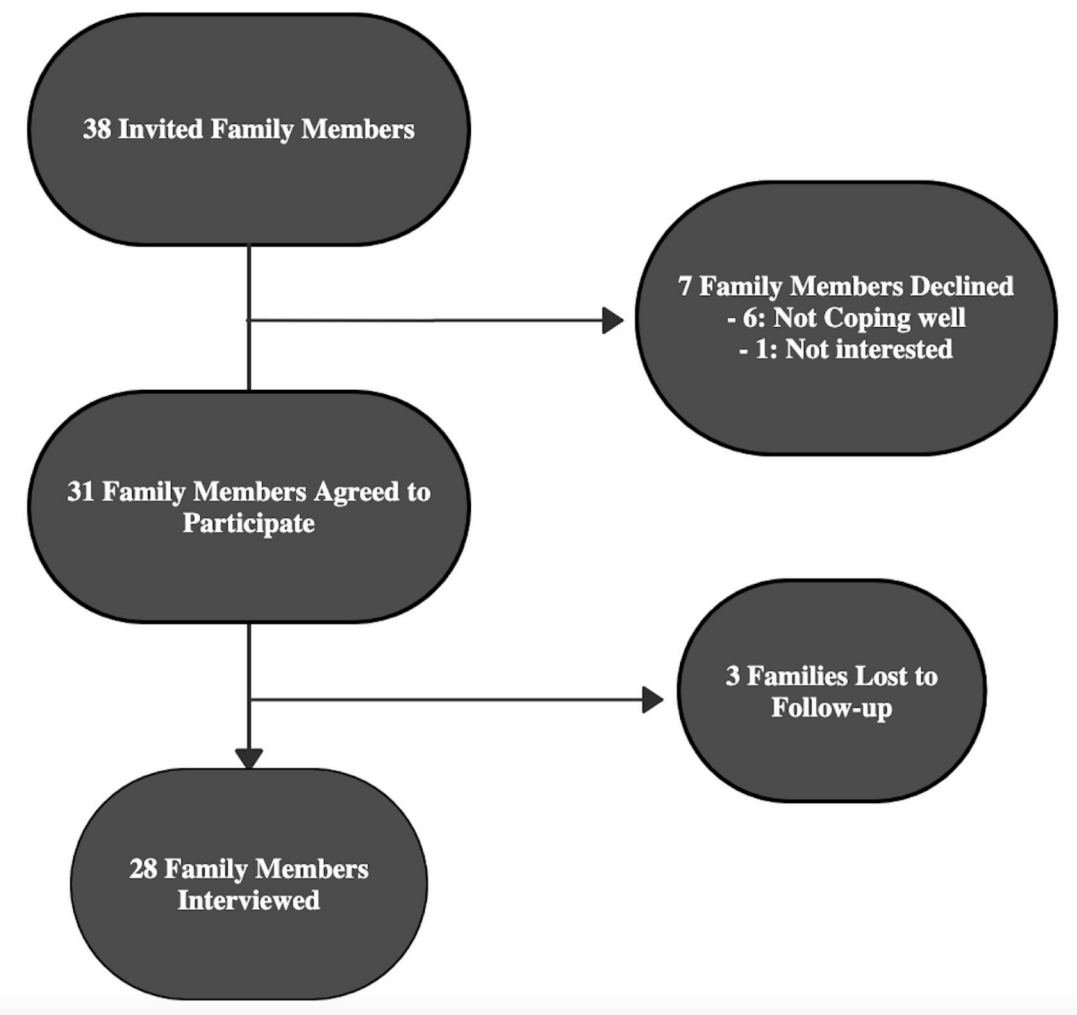

Figure 1 Family participant flow diagram. Summary of recruitment flow for eligible families.

compassionate care, sometimes casting their own sacrifice in solidarity with efforts that clinicians made in service to the community. They also shared adaptations to traditional postmortem practices and rituals that influenced their grieving.

\section{Acquiescence to pandemic-related restrictions}

Despite the suffering and loss endured by families during the pandemic, acquiescence to the pandemic-related restrictions was acknowledged as a civic duty. Families explained how being away from their loved one during their final days reflected their recognition of the rationale for jurisdictional rules. In surrendering their hospital visits to minimise transmission risk, many participants invoked the concept of social solidarity and safeguarding the community.

I never abused the procedures that we had to follow. We try and understand because it was for the greater good... it was for the best... they had to take some precautions. (Partner)

In a poignant example of accepting the risk of missing her husband's final moments, one participant described her decision of a delayed hospital visit in terms of protecting others from possible viral transmission:

I told [the doctor] I had been dealing with the public so I would need to go home anyhow and shower and change my clothing before I came up to the hospital and when I was enroute home, the Charge Nurse called and she said, 'You know, if you do what you say you're going to do, he may not be here.' And I said, 'Well, you know, [patient's name] would have it no other way.' He wouldn't want me coming up and contaminating the hospital. (Partner)

Some family members assented to the necessary restrictions but considered the perceived changes in care as a casualty of the pandemic:

She was in hospital there and I couldn't visit her there and with the hearing impairment and sight impairment [it was] even harder for her because now she's in a strange place. Everyone's wearing PPE, which I don't blame, and I'm sure the people couldn't spend as much time as they may have wanted to with her because of the situation...I guess she was just collateral damage from whole COVID situation. (Son)

\section{Loving and grieving from afar}

The experiences of being separated from a loved one during periods of critical illness and up to the moment of death were universally described as agonising. Being kept apart led many family members to experience decisional dilemmas regarding safety for themselves and others. Participants wondered if their visits could introduce the virus, including to their dying loved one who was not infected. One participant asked himself if he should 'take the risk of where I get my mother sick' (son). Another family member remarked on a possible conflicting sense of duty for people who would otherwise visit hospitalised patients, 


\begin{tabular}{|c|c|}
\hline Characteristics & $\mathrm{n}=\mathbf{2 8}$ \\
\hline Age, years, mean (SD) & $55.5(12.0)$ \\
\hline Female $\mathrm{n},(\%)$ & $22(78.6)$ \\
\hline \multicolumn{2}{|l|}{ Ethnicity, n (\%) } \\
\hline White & $24(85.7)$ \\
\hline Indigenous & $2(7.1)$ \\
\hline Arabic & $1(3.6)$ \\
\hline East Asian & $1(3.6)$ \\
\hline \multicolumn{2}{|l|}{ Religion, n (\%) } \\
\hline Christian & $18(64.3)$ \\
\hline Atheist & $5(17.9)$ \\
\hline Agnostic & $4(14.3)$ \\
\hline Indigenous & $1(3.6)$ \\
\hline \multicolumn{2}{|l|}{ Relationship to deceased, n (\%) } \\
\hline Child & $12(42.9)$ \\
\hline Parent & $4(14.3)$ \\
\hline Friend & $4(14.3)$ \\
\hline Sibling & $3(10.7)$ \\
\hline Partner/spouse & $2(7.1)$ \\
\hline Relative by marriage (in-law) & $2(7.1)$ \\
\hline Grandchild & $1(3.6)$ \\
\hline \multicolumn{2}{|c|}{ Ward at patient's time of death, $\mathrm{n}(\%)$} \\
\hline Intensive care unit & $23(82.1)$ \\
\hline COVID-19 ward & $2(7.1)$ \\
\hline Acute medical stepdown unit & $1(3.6)$ \\
\hline Palliative care suite & $1(3.6)$ \\
\hline Hospital medical ward & $1(3.6)$ \\
\hline
\end{tabular}

In this table, we report characteristics of interviewed family members and location of the patient's death. The COVID-19 ward cared for acutely ill COVID-19 patients; those requiring high-flow nasal cannula or $\mathrm{FiO}_{2}>0.70$ were transferred to the intensive care unit.

$\mathrm{FiO}_{2}$, fractional inspired oxygen.

such as a case worker from a group home, because 'she wouldn't want to bring it back there' (son).

Deprived of the chance to be physically present before and during the dying process haunted most families. Some referenced their absence at the bedside to be detrimental to a patient's recovery. While technology provided opportunities for continued connections, a few families found the virtual visits distressing, and occasionally shocking, especially witnessing the trajectory of their loved one's progressive decline. Others described difficulty understanding how much their loved one had decompensated in hospital without seeing it first-hand.

And then, we had that twoweek window where we couldn't go in and then, when I pushed again to get in there, [my mother] was a completely different person...You couldn't get a reaction. (Daughter)

Some described this lack of in-person contact as impairing their ability to make informed end-of-life decisions, especially related to resuscitation directives.

You know, whatever protocol is necessary, I will follow that. I need to physically see her to make that decision. I can't make that decision over the phone. (Daughter)

Families were concerned that the hardship that patients underwent were worse than theirs during the pandemic. The anguish of separation was particularly difficult for families with loved ones with physical disabilities including visual and auditory impairment. The most frequently expressed worry was about patients' ability to communicate with the care team due to sensory and/or cognitive impairments or language barriers.

With the hearing impairments and sign impairments... [it's] even harder for her because now she's in a strange place. (Son)

While all participants grieved the loss of the chance to be physically present at the time of death, one family member acknowledged how this lack of physical presence also averted the anticipated trauma of witnessing the final moments.

I know it sounds awful, I really wanted to be there for her, but that's a really big burden to carry with you for the rest of your life. (Sister)

Imagining their loved one dying alone many months after the death during interviews, all participants expressed heartache.

I'll never know what those threeweeks were like. I don't know what an eternity it was. My worst thing was, does he feel forsaken by us? (Partner)

\section{Respect and appreciation for clinicians}

Families expressed gratitude for the social workers and chaplains who spent countless hours supporting them when their 'world is falling apart' (artner). Many participants derived comfort from frequent, open communication:

They always called me back. Even if it was my third call of the day, it was okay. And they gave me an update, whether it was 'no change' or whatever change it was, if there was a change. I didn't feel like I was bugging them. (Daughter-in-law)

Being able to rely on clinicians to deliver supportive messages to their loved one was greatly appreciated.

I said, please make sure that he knows that I'm calling....that I love him very much. I care [pause] and that, you know, due to COVID, we can't be with him. (Partner) 
This family-centred contact with clinicians was greatly valued, creating connections and intimate moments whenever possible, particularly at the end:

They did call me and ask me what I wanted to say to him before he went, if he went through the night. That was the biggest thing for me. (Son)

During both in-person and virtual visits, family members observed acts of compassion performed collaboratively by nurses, often with other clinicians, such as humanising the environment and recognising the dignity of the patient through personal care.

Somebody took the care to shave him properly. And, and it just put a smile on my face, you know, that, there was some dignity. You know that even though he was so sick, that somebody cared enough. I'll always remember that. Always. (Partner)

\section{Postmortem impacts of COVID-19}

Many adaptations to postmortem practices were described by those unable to visit the hospital, including identification of the body. Contrasted with typical practices of confirming a loved one's identity guided in-person by funeral home staff, one participant described a request to identify her deceased sister on a digital photo over email.

I think of what she looked like when she was dying and I think about the picture she sent me for confirmation, the funeral home - the picture they sent from the morgue... I haven't looked at it again but it's there because I don't know whether I should delete it or not. Like, it feels wrong to delete it but I don't want to look at it. (Sister)

After being barred from hospital, and in some cases from long-term care residences before a patient's hospitalisation, funeral service limitations added another layer of loss for families who had to defer or forgo celebrations of their loved one's life.

It feels like, if you don't have a funeral, you're not honouring her. It's just like she didn't matter. You know? She's just, like, in a box on the mantle and we didn't come together and talk about her and show our love for her. It just feels like [pause] she was just like a blip. (Sister)

Many families described missing out on the comfort of community gatherings associated with the usual postmortem rituals.

When you go to funeral home and you have those two days or whatever, people come and they express their feelings and they comfort you, which wasn't part of this. We only had two hours at the funeral home and that was it. (Partner)

By contrast, exemption from social obligations during bereavement was also referred to as 'blessings in disguise' (mother, daughter). Pandemic restrictions led to changes in conventional ceremonies, which some participants welcomed. Strict lockdown orders necessitated many individuals to work from home and keep services small. Some families found relief in the permission for privacy granted by the pandemic.

But COVID, in a weird way, was a bit of a blessing in terms of that because I have been working from home since March so I did take a little bit of time off of work. But then, you know, obviously, it's not like the week that I took off fixed everything. I was still kind of hurting from it, it was nice to be able to work and just be by myself and if I needed to, cry, you know. I'd have to like, run to the bathroom at work [pause] I could just kind of do it in my own space. (Daughter)

Other families described domestic adaptations, having: 'a celebration of life in the backyard' (father). Some religious and secular services used video platforms. Streaming live ceremonies provided relatives opportunities to offer condolences from a distance.

With regards to the church ceremony and also the gravesite ceremony, they broadcasted it live on FaceTime. My brother and our other family in the U.S. and back in Poland and Australia were able to watch at that time. (Son)

Some communities came together in solidarity for hurting families. Local demonstrations of support were recounted, including an instance when a hearse carried a patient's remains to the gravesite.

We called one of the neighbours to come [pause] they all wanted to come but they couldn't [pause] and we told them that we were going to pass by the house for his last time before going to the cemetery. And then they all stood by the front lawn saying goodbye. (Partner)

\section{DISCUSSION}

Findings from this study highlight the impact that the COVID-19 pandemic has had on family members who have lost a loved one in hospital. Families expressed acquiescence to pandemic-related restrictions, underscoring a sense of unity for the public good. Nevertheless, the inability to be physically present in hospital had myriad consequences for relatives and friends of dying patients. Participants described multiple distinct losses beyond the death itself, in terms of bedside vigils foregone and rushed rituals afforded by usual mourning practices. Families observed solidarity among clinical staff and sense of unity with staff while entrusting their loved one's care to the clinical team. Although families valued clinicians' efforts to mitigate the negative impact of infection control restrictions, these efforts did not prevent their profound and enduring grief. 
Family perspectives about hospitalised dying relatives during the pandemic have been reported in selfadministered public surveys ${ }^{1315}$ and two other qualitative studies. ${ }^{12} 16$ One study of 19 families of patients who died in hospital or another setting in the $\mathrm{UK}^{12}$ and a report of 19 relatives of patients who died in an intensive care units in France ${ }^{16}$ also underscored the impact of physical separation on relatives' experiences of bereavement. Our findings confirm these reports of profound loss described by family members whose final connections and postmortem rituals to honour their loved one were subverted by pandemic-related infection control measures. Delaying family contact postmortem longer than prior research, ${ }^{12} 16$ the interviews we conducted $6-16$ months postmortem indicate vivid recall and suggest enduring grief. Our findings also differ from previous reports describing tension and diminished trust between families and critical care staff, ${ }^{16}$ instead highlighting how connections and open communication cultivated with clinicians was a comforting aspect of their experience, perhaps facilitating bonding between families and clinicians, ultimately fostering confidence in the healthcare team. ${ }^{31}$

Contrary to the social division that can result from imposed public health restrictions, ${ }^{32}$ our study differs from other research in that it revealed a general collective attitude of acceptance. Although public health policies often employ a utilitarian approach, requiring individuals to make personal sacrifices for the greater good, this tension between personal and collective interests can be further exacerbated in states of emergency. ${ }^{33}$

Reflections on what stayed with families postmortem illuminate some suggestions for future end-of-life practice under continuing pandemic restrictions. The angst of perceiving their loved one as dying alone ${ }^{15}$ calls for frequent, flexible and transparent communication. Additional attention is needed for patients with language barriers or physical and/or cognitive impairments, who are especially impacted by the absence of family members. Ensuring that visual aids, hearing devices or language translation assistance is available may aid communication for the most vulnerable and help to alleviate family distress. Digital solutions to augment phone and in-person connections can help to share details of patients' status, trajectory and care but need technical and emotional preparation and support. Dedicated efforts to humanise the clinical space with personal affects, in conjunction with patient-centred acts of compassion, were small yet impactful ways to comfort families from afar. Additional strategies to promote individualised patient and familycentred EOL care in hospital and create personalised adaptations to memorial services and life celebrations could assist in easing family grief.

Strengths of this study include a focus on family experiences both within and beyond hospital exposure. Interview data reflect a range of relationships; the participation rate was $74 \%$. Limitations include a predominantly white, English-speaking sample from the first pandemic wave in the context of a publicly funded healthcare system. ${ }^{34}$
Results may differ for individuals with more videoconferencing access and ability, in communities with a different COVID-19 prevalence and vaccination penetrance and in different healthcare systems.

\section{Conclusion}

This study highlights the impact of public health measures on family member experiences of the death of a hospitalised loved one. Profound loss and enduring grief were described by those whose final connections were constrained by pandemic restrictions. Despite the overwhelming sacrifices made, families reported acquiescence in the name of population health and solidarity with clinical staff caring for their loved one. Clinicians and public health officials should consider these familyinformed perspectives when generating crisis guidelines and future administrative policies to improve EOL care for hospitalised patients.

\section{Author affiliations}

${ }^{1}$ Department of Medicine, McMaster University, Hamilton, Ontario, Canada ${ }^{2}$ Department of Family Medicine, McMaster University, Hamilton, Ontario, Canada

${ }^{3}$ School of Rehabilitation Sciences, McMaster University, Hamilton, Ontario, Canada ${ }^{4}$ Department of Health Research Methods, Evidence and Impact, McMaster University, Hamilton, Ontario, Canada

${ }^{5}$ Department of Critical Care Medicine, St. Joseph's Healthcare Hamilton, Hamilton, Ontario, Canada

${ }^{6}$ Department of Spiritual Care, St. Joseph's Healthcare Hamilton, Hamilton, Ontario, Canada

${ }^{7}$ University of California Los Angeles, Los Angeles, California, USA

${ }^{8}$ Department of Critical Care Medicine, University of Calgary Cumming School of Medicine, Calgary, Alberta, Canada

Contributors All authors (BD, DJC, MV, MS, DBV, AB, TV, JCD, AC, FJC, NH, JH, THN, FT, MS and KF) made equal contributions to the analysis and interpretation of the data. BD, DJC and MV were responsible for the conception and design of the study. MS and BD were responsible for the acquisition of the data. DJC, BD, MS, THN and MV were responsible for the analysis of the data. All authors reviewed and contributed to the final draft of the manuscript. All authors approve the current submission. BD and DJC act as guarantors.

Funding This study was peer-review funded by Services Incorporated of Ontario (Grant Number R21-16), the McMaster University Department of Medicine Paul 0'Byrne Research Grant and the Canadian Institutes for Health Research. The researchers had full independence from funders and all authors, external and internal, had full access to all data (including statistical reports and tables) in the study and can take responsibility for the integrity of the data and the accuracy of the data analysis. DJC holds a Research Chair in Intensive Care Medicine from the Canadian Institutes for Health Research.

Disclaimer The funders had no role in study design and conduct of the study; collection, management, analysis and interpretation of the data; or preparation, review or approval of the manuscript.

Competing interests None declared.

Patient consent for publication Not applicable.

Ethics approval This study involves human participants and was approved by Hamilton Integrated Research Ethics BoardID: 11005. Participants gave informed consent to participate in the study before taking part.

Provenance and peer review Not commissioned; externally peer reviewed.

Data availability statement No data are available. No data are available for public use. This study includes qualitative data generated from interviews with families. To protect the confidentiality of families included in this study, we will not be sharing data gained from interview. Families included in this work did not agree for data generated from interviews to be shared and publicly available.

Supplemental material This content has been supplied by the author(s). It has not been vetted by BMJ Publishing Group Limited (BMJ) and may not have been 
peer-reviewed. Any opinions or recommendations discussed are solely those of the author(s) and are not endorsed by BMJ. BMJ disclaims all liability and responsibility arising from any reliance placed on the content. Where the content includes any translated material, BMJ does not warrant the accuracy and reliability of the translations (including but not limited to local regulations, clinical guidelines, terminology, drug names and drug dosages), and is not responsible for any error and/or omissions arising from translation and adaptation or otherwise.

Open access This is an open access article distributed in accordance with the Creative Commons Attribution Non Commercial (CC BY-NC 4.0) license, which permits others to distribute, remix, adapt, build upon this work non-commercially, and license their derivative works on different terms, provided the original work is properly cited, appropriate credit is given, any changes made indicated, and the use is non-commercial. See: http://creativecommons.org/licenses/by-nc/4.0/.

\section{ORCID iDs}

Brittany Dennis http://orcid.org/0000-0002-3691-5400

Joanna C Dionne http://orcid.org/0000-0002-9401-6868

Kirsten Fiest http://orcid.org/0000-0002-7299-6594

\section{REFERENCES}

1 Grasselli G, Pesenti A, Cecconi M. Critical care utilization for the COVID-19 outbreak in Lombardy, Italy: early experience and forecast during an emergency response. JAMA 2020;323:1545-6.

2 Onder G, Rezza G, Brusaferro S. Case-fatality rate and characteristics of patients dying in relation to COVID-19 in Italy. JAMA 2020;323:1775-6.

3 Ruan Q, Yang K, Wang W, et al. Clinical predictors of mortality due to COVID-19 based on an analysis of data of 150 patients from Wuhan, China. Intensive Care Med 2020;46:846-8.

4 Wang SSY, Teo WZY, Yee CW, et al. Pursuing a good death in the time of COVID-19. J Palliat Med 2020;23:754-5.

5 Zhou F, Yu T, Du R, et al. Clinical course and risk factors for mortality of adult inpatients with COVID-19 in Wuhan, China: a retrospective cohort study. Lancet 2020;395:1054-62.

6 Lewnard JA, Lo NC. Scientific and ethical basis for social-distancing interventions against COVID-19. Lancet Infect Dis 2020;20:631-3.

7 Zulman DM, Haverfield MC, Shaw JG, et al. Practices to foster physician presence and connection with patients in the clinical encounter. JAMA 2020;323:70-81.

8 Hanna JR, Rapa E, Dalton LJ, et al. Health and social care professionals' experiences of providing end of life care during the COVID-19 pandemic: a qualitative study. Palliat Med 2021;35:1249-57.

9 Galehdar N, Kamran A, Toulabi T, et al. Exploring nurses' experiences of psychological distress during care of patients with COVID-19: a qualitative study. BMC Psychiatry 2020;20:489.

10 Cook DJ, Takaoka A, Hoad N, et al. Clinician perspectives on caring for dying patients during the pandemic: a mixed-methods study. Ann Intern Med 2021;174:493-500.

11 Hart JL, Turnbull AE, Oppenheim IM, et al. Family-Centered care during the COVID-19 era. J Pain Symptom Manage 2020;60:e93-7.

12 Hanna JR, Rapa E, Dalton LJ, et al. A qualitative study of bereaved relatives' end of life experiences during the COVID-19 pandemic. Palliat Med 2021;35:843-51.
13 Mayland CR, Hughes R, Lane S, et al. Are public health measures and individualised care compatible in the face of a pandemic? A national observational study of bereaved relatives' experiences during the COVID-19 pandemic. Palliat Med 2021;35:1480-91.

14 Hugelius K, Harada N, Marutani M. Consequences of visiting restrictions during the COVID-19 pandemic: an integrative review. Int J Nurs Stud 2021;121:104000.

15 Feder S, Smith D, Griffin H, et al. "Why couldn't I go in to see him?" Bereaved families' perceptions of end-of-life communication during COVID-19. J Am Geriatr Soc 2021;69:587-92.

16 Kentish-Barnes N, Cohen-Solal Z, Morin L, et al. Lived experiences of family members of patients with severe COVID-19 who died in intensive care units in France. JAMA Netw Open 2021;4:e2113355.

17 Aslakson RA, Cox CE, Baggs JG, et al. Palliative and end-of-life care: prioritizing compassion within the ICU and beyond. Crit Care Med 2021;49:1626-37.

18 Kanaris $\mathrm{C}$. Moral distress in the intensive care unit during the pandemic: the burden of dying alone. Intensive Care Med 2021;47:141-3.

19 Rosenbaum L. Harnessing our humanity - how Washington's health care workers have risen to the pandemic challenge. $N$ Engl J Med 2020;382:2069-71.

20 Curley MAQ, Broden EG, Meyer EC. Alone, the hardest part. Intensive Care Med 2020;46:1974-6.

21 Onwuteaka-Philipsen BD, Pasman HRW, Korfage IJ, et al. Dying in times of the coronavirus: an online survey among healthcare professionals about end-of-life care for patients dying with and without COVID-19 (the CO-LIVE study). Palliat Med 2021;35:830-42.

22 Neergaard MA, Olesen F, Andersen RS, et al. Qualitative description - the poor cousin of health research? BMC Med Res Methodol 2009;9:52.

23 Sandelowski M. What's in a name? Qualitative description revisited. Res Nurs Health 2010;33:77-84.

24 Hsieh H-F, Shannon SE. Three approaches to qualitative content analysis. Qual Health Res 2005;15:1277-88.

25 Fram SM. The constant comparative analysis method outside of Grounded theory. The Qualitative Report 2013;18:1-25.

26 UKEvSI F. A companion to qualitative research. London; Thousand Oaks, CA: Sage Publications, 2004.

27 Cutcliffe JR, McKenna HP. Expert qualitative researchers and the use of audit trails. J Adv Nurs 2004;45:126-33.

28 Vanstone M, Neville TH, Clarke FJ, et al. Compassionate end-of-life care: mixed-methods multisite evaluation of the 3 wishes project. Ann Intern Med 2020;172:1-11.

29 Takaoka A, Tam B, Vanstone M, et al. Scale-up and sustainability of a personalized end-of-life care intervention: a longitudinal mixedmethods study. BMC Health Serv Res 2021;21:218.

30 Vanstone M, Sadik M, Smith O, et al. Building organizational compassion among teams delivering end-of-life care in the intensive care unit: the 3 wishes project. Palliat Med 2020;34:1263-73.

31 Montauk TR, Kuhl EA. COVID-related family separation and trauma in the intensive care unit. Psychol Trauma 2020;12:S96-7.

32 Harris CE. The conflict of public health law and civil liberties: the role of research data and first Amendment law. Am J Med 2021;134:1312-3.

33 Chadwick R. COVID-19 and the possibility of solidarity. Bioethics 2020;34:637.

34 Hapuhennedige S. Public health experts are learning from Canada's anti-mask protests. CMAJ 2020;192:E1274-5. 